Article

\title{
The Effectiveness of the Multilateral Coalition to Develop a Green Agricultural Products Market in China Based on a TU Cooperative Game Analysis
}

\author{
Mingjun Deng ${ }^{1}$, Guocheng Xiang ${ }^{2, *}$ and Shuntian Yao ${ }^{1}$ \\ 1 Business School, Hunan University of Science and Technology, Xiangtan 411201, China; \\ mjdeng@hnust.edu.cn (M.D.); shuntianyao@hotmail.com (S.Y.) \\ 2 College of Economics and Trade, Hunan University of Commerce, Changsha 410205, China \\ * Correspondence: gcxiang@hnust.edu.cn; Tel.: +86-0731-5829-0171
}

Received: 28 March 2018; Accepted: 5 May 2018; Published: 8 May 2018

\begin{abstract}
Green agriculture can improve biodiversity, increase farmers' income, reduce agricultural non-point source pollution, solve food safety issues, and will be an important way to promote sustainable development in China. At present, the green transformation of China's agriculture has encountered a bottleneck in the development of a green agricultural product market. How to develop a green agricultural product market has become an issue worthy of in-depth study in the academia. Previous studies have already given persuasive explanations for the inability to form a green agricultural product market, but few have explored its development path from the angle of cooperation. By employing the method of a Transferable Utilities (TU) cooperative game, and based on theoretical analyses and hypothetical data, this thesis aims to prove the effectiveness of the multilateral coalition to develop the green agricultural product market in China. The results show the effectiveness of the developed model of the green agricultural product market in which producers, consumers, food safety inspection departments, and e-commerce platforms cooperate with each other. This model meets the objective needs of the times and that of the market economy. According to the marginal contribution value of participants in different coalition orders, this thesis finds 6 kinds of coalition orders. When producers and consumers of green agricultural products enter the coalition in the last place, the marginal contribution value is maximized, which reflects the importance of the supply side and demand side of green agricultural products. In other words, the development of the green agricultural product market is a dynamic process-determined by consumers and promoted by producers-in which both sides promote and restrict each other. Finally, this article presents two policy recommendations: at the national level, to clearly proposes a strategy to build a green agricultural product e-commerce platform in China and to launch a pilot application for the specialized e-commerce platform for green agricultural products in the Guizhou province.
\end{abstract}

Keywords: green agricultural products market; multilateral coalition; TU cooperative game; Shapley value; e-commerce platform

\section{Introduction}

\subsection{Green Agriculture and Sustainable Development in China}

Green agriculture is a resource-conserving and environment-friendly sustainable development agriculture and requires reasonable applications of inputs, including pesticides, fertilizers, veterinary drugs, additives, and so forth to prevent pollution through toxic and harmful matters to the produce or links to food processing [1]. It is a mature green food industry development model that includes the production, processing, and marketing of green agricultural products, and involves pollution-free 
agricultural products, green food, and organic food [2]. This has the same essential connotation as the concept of organic agriculture defined by the UN's Food and Agriculture Organization in 1990.

The relationship between green agriculture and sustainable development: (1) green agriculture ensures human health. Green agriculture aims for the conservation of soil and water; organic products require the use of natural manure and the lack of fertilizers or chemical products in the production process. In the processing stage of organic food, the use of additives and chemical substances is restricted. Nutrition specialists argue that organic products are richer in nutrients, vitamins, and antioxidants, which is beneficial for one's health because they help increase one's immunity and reduces the risk of food allergies [3,4]. (2) Green agriculture ensures biodiversity and environmental health. Green agriculture is a very important field for ensuring the sustainability and the transition to a green economy, a field that has a major impact on the natural environment. Green agriculture does not use genetically modified organisms and strictly controls the use of fertilizers, pesticides, hormones, and antibiotics. Thus, it implements crop rotations and waste recycling $[5,6]$. (3) Green agriculture helps improve soil fertility. Green agriculture restores and improves soil fertility by increasing the natural and sustainable nutrient inputs, diversifying crop rotations, and integrating animal husbandry and planting [7]. (4) Green agriculture helps increase farmers' income. Based on over 120 studies, the results show that even if organic farming produces approximately $10-18 \%$ less than conventional farming, the additional prices (up to $30 \%$ higher) that customers pay for green products will cover the costs of organic farmers and ensure their profitability [8].

At present, there are four major challenges to the sustainable development of the agriculture and rural areas in China: (1) a high consumption of resources but a low level of recycling. The application rate of China's chemical fertilizers and pesticides accounts for more than one-third of the total global consumption, but in 2005, the Department of Crop Production stated that the actual utilization of the total organic fertilizer resources in China was less than $40 \%$. (2) Serious environmental pollution. Excessive ammonia emissions from China's agriculture continue to push up China's $\mathrm{PM}_{2.5}$ index [9]. Large amounts of nitrogen, phosphorus, and chemical oxygen demand emissions cause serious water pollution and the excessive application of chemical fertilizers as pesticides leads to soil contamination. (3) Serious issues on food and agricultural product safety. China's agricultural over-fertilization accelerates soil acidification, lessens the number of organic matters, and causes soil hardening, posing a threat to China's long-term food safety. Food safety accidents occur frequently in China, for which many popular but low-end products are to blame, and the questionable quality of many high-end products are exposed. (4) According to the current national rural poverty standards, by the end of 2017, China's rural poor population will number 30.46 million people. The remaining poor people have a deeper level of poverty, higher poverty reduction costs, and a greater difficulty in getting out of poverty.

In summary, developing a green agriculture will be an important way to promote sustainable development in China.

\subsection{China's Green Agricultural Development Has Market Bottlenecks}

According to the "Green Food Statistical Yearbook" released by the China Green Food Development Center [10], the number of certified green-food firms and products in 2001-2015 are demonstrated in Figure 1. The number of certified green-food firms and products increased by 6.87 times and 8.74 times, respectively. However, in reality, the number of certified green-food products is inconsistent with the size of the green-food product market in China. The variety and quantity of green-food products circulating in the market are very limited and these green foods mainly appear in large shopping malls or e-commerce platforms. It can be seen that China only attaches importance to the certification of green foods and does not pay attention to the development of the green food market. 


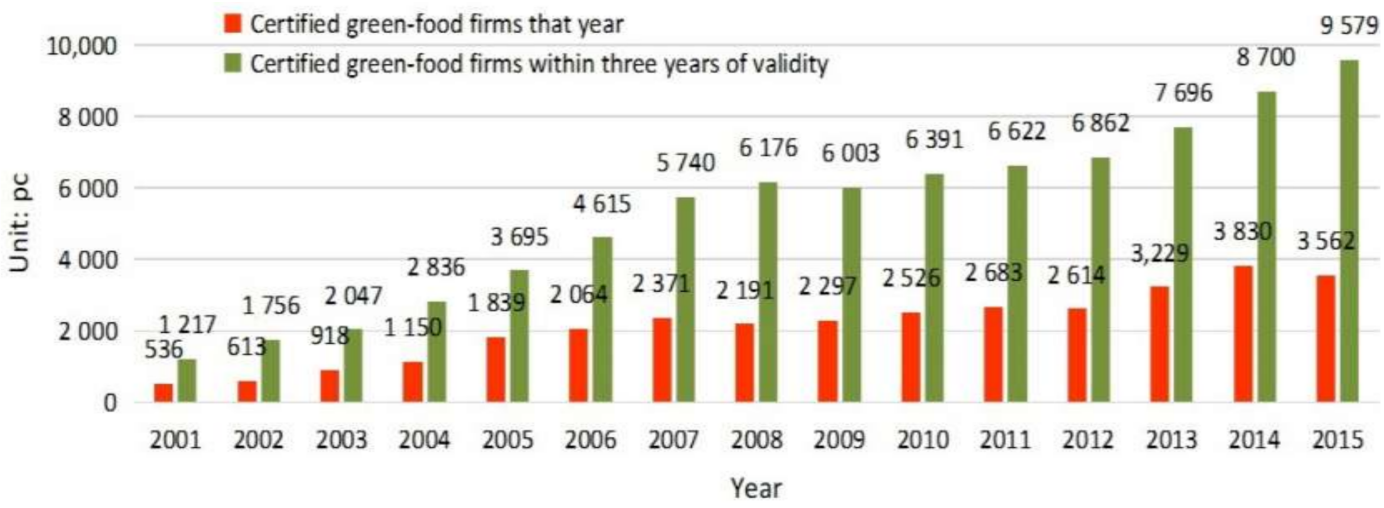

(a) The number of China's certified green-food firms.

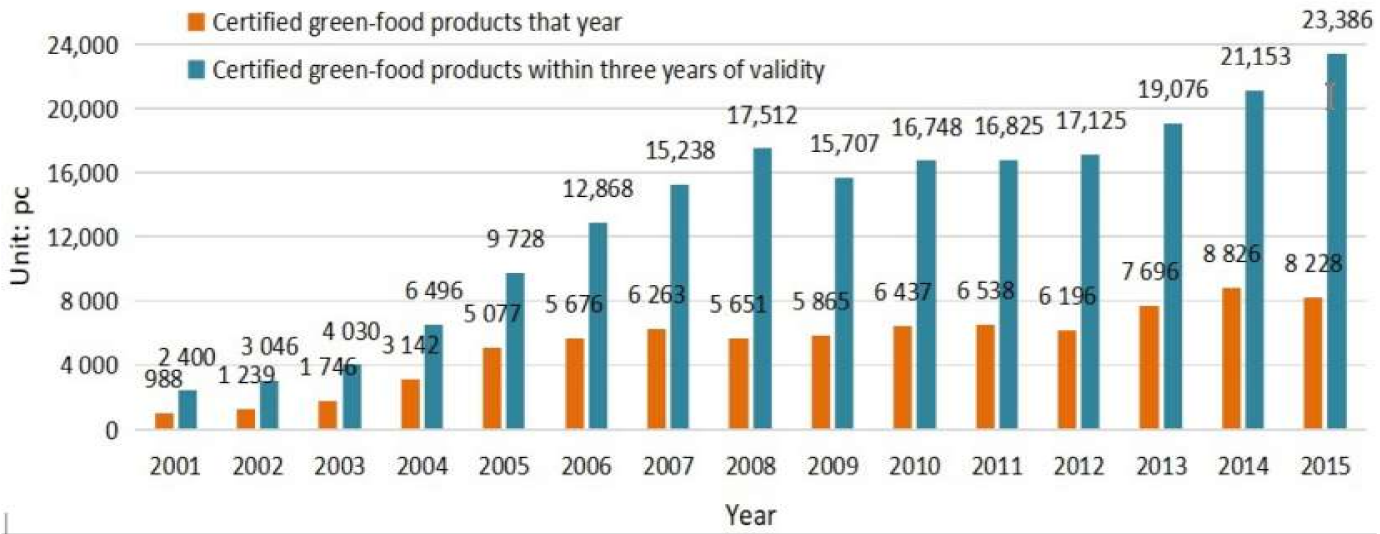

(b) The number of China's certified green-food products.

Figure 1. The number of certified green-food firms and products (2001-2015). Data source: China Green Food Development Center, http:/ /jiuban.moa.gov.cn/sydw/lssp/zl/tjnb/lssptjnb/.

Due to the "lemon market" dilemma and the trust crisis of green agricultural products, the development of China's green agricultural products market has been hindered. For example: (1) in August 2014, the Evergrande Group poured a huge investment to enter the green agricultural product market in a high-profile manner. However, due to sluggish sales, it eventually sold its assets in the grain, oil, and dairy industries at the end of September 2016; (2) the Fairy Maiden Vegetable Production and Marketing Cooperative (the cooperative is $18 \mathrm{~km}$ away from the college where the first author is located. The first author investigates the cooperative every year.) in Xiangtan, China, has more than 800 acres of land and meets the requirements for green-food planting. In August 2014, the certification of green products for 14 vegetable varieties was successful. In 2016, the green certification was renewed and five varieties of green-food certification were added. However, due to sluggish sales, it has been losing money for many years and the area of green agricultural products is less than 100 acres; (3) there is no profit for all e-commerce platforms engaged in the sale of green agricultural products in China. Among them, the Vegetable Stewardship High-quality Agricultural Product Ordering Platform has invested a total of 35 million yuan in 4 years, but it is still operating at a loss; the Wuhan House Easy has covered electronic boxes for more than 1200 communities in two and a half years and has invested over 6000 million yuan in total; although its daily turnover is not small, it is basically in a state of loss.

Therefore, solving the problem of the development of the green agricultural product market has become the key to the green transformation of China's agriculture and it is an issue worthy of in-depth study in the academia.

The rest of this paper is organized as follows. Section 2 reviews the literature. Section 3 constructs the conceptual model of the relationship between the main bodies of the green agricultural product 
market. Section 4 is the non-empty core verification and Shapley value solution of the cooperative game in the green agricultural product market. Section 5 is the discussion. Section 6 is conclusions and policy implications.

\section{Literature Review}

\subsection{Research on the Supply of Green Agricultural Products}

From the perspective of effective supply, Ni [11] believes that the barriers in the development of China's green agricultural product industry are the insufficient supply of pollution-free agricultural products and non-staple food products that fail to meet the consumer's demands on green consumption such as fruits, vegetables, and meat. Domestic and foreign scholars have different interpretations on the insufficient market supply of green agricultural products: (1) enterprises and farmers will start a game due to information asymmetry, technical limitations, and market risks of high-quality agricultural products, and both enterprises and farmers have certain short-sighted behaviors and the tendency of opportunism. Driven by profits, enterprises will swing, weigh, and balance on the investment level of quality and safety of the agricultural products [12]; (2) Although farmers cooperate with enterprises and accept high-level safety standards, at the initial stage, the product output will decline and the food quality is unstable [13]; (3) in contract agriculture, a certain degree of incentives and disincentives stimulate and propel both enterprises and farmers to enhance investment in products quality and safety. It can easily lead to the negative phenomena of squeezing the margins of farmers [14]; (4) many factors are also involved in whether farmers can adopt a green or organic agricultural production model, including how big the production area is; whether farmers participate in the training of agricultural products' quality and safety; whether they sign agricultural product purchases and sale contracts with agricultural industrialization organizations; whether they have received technical instruction on agricultural production; how strict the government supervision and regulations are, together with individual characteristics such as the farmer's gender, age, ability to perceive chemical pesticide residue hazards, years of schooling, and understanding of organic foods [15,16]. The above research results show that the positive interaction and coordination between enterprises and farmers can improve the quality and safety of agricultural products, but it is limited by the high risks in the consumer market of green agricultural products, which stems from the failure to foster the competition effect and contagion effect of the economies of scale and the credence goods market [17]. Both enterprises and farmers do not necessarily provide consistently high-quality agricultural products. In the absence of traceability, moral hazards and the inability to establish a green agricultural products market are likelier to be encountered. Consequently, green agricultural producers have to retreat from the green agricultural products market or resort to business transformation.

\subsection{Research on the Consumption of Green Agricultural Products}

The previous empirical analysis shows that the factors that affect consumers' willingness to pay for quality agricultural products include the consumers' ability to pay [18], the consumer preferences [19], the consumer's hedonic attitudes [20], the consumer's concern about food quality and safety [21], the consumer's knowledge and trust in food quality and safety standards [22], and the consumer's trust level of information carried on food labels [23]. As China enters the middle-income stage of development and the food safety situation becomes increasingly serious, more and more consumers have begun to pay attention to the issue of food quality and safety and there has been a demand for the purchasing quality and safe edible agricultural products. However, there is a strange phenomenon in China today. On the one hand, consumers are increasingly demanding food quality, and some foods-such as milk powder, that close attention needs to paid to their quality and safety-are even desperate to turn to overseas purchases; however, on the other hand, the consumers' willingness to pay for high-quality edible agricultural products such as "green food" and "organic food" in China is not strong and the premium level received from the relevant research is not high [24]. For example, Yu and 
Zhao [25] found that consumers are willing to pay a premium of $20 \%$ to $30 \%$ for green agricultural products. $\mathrm{Hu}$ [26] found that although consumers' willingness to pay for traceable green pork is significantly higher than green pork that is not traceable, they are only willing to pay a premium of $10 \%$ to $20 \%$ for traceable green pork. Zhao [27] found that the traceable food premium level is only $9 \%$ to $12 \%$. The importance of credence attributes in predicting the consumers' attitudes and purchase intentions has been proved in a considerable number of studies [28]. The above research results show that the consumer's trust is the key driver for the development of China's green agricultural products market, allowing consumers to receive enough information about the quality standards and certifications of the products they are willing to purchase and being able to trust this information enough. Then the consumers' willingness to purchase and pay premium levels for the product will increase and green agricultural producers will have the possibility of profitability.

\subsection{Research on Game Theory of Buyers and Sellers of Green Agricultural Products}

Green agricultural products have safe and trustworthy streaks, which means that the buyers and sellers have a serious information asymmetry on the safety rate that may lead to market failure [29]. McCluskey [30] studied the game behaviors of the buyers and sellers of organic agricultural products under the situation of information asymmetry. The results demonstrate that high-quality creditable products need a relationship of repeated purchases and third-party monitoring. If false quality claims could be avoided, producers will gain more profits from the higher prices with lower production costs. The price of organic agricultural products and the difference between the price of organic agricultural products and the cost of ordinary agricultural products will determine the minimum necessary monitoring level. Jin and Zheng [31] studied the game behavior in the green agricultural products market and found that the Nash equilibrium solution of the game between enterprises and consumers is the small-scale production and small-scale purchase. It indicates that the "prisoner's dilemma" phenomenon in the green agricultural products market is a result of the rational choice of enterprises and consumers amid the current constraints: a phenomenon of market failure. When adverse selection behavior prevails in markets, green agricultural products are driven out of the market; ordinary agricultural products flood the market so that the transactions of green agricultural products diminish. $\mathrm{Li}$ and Shi [32] constructed a two-phase trading model that includes adverse selection and moral hazards. The decision makers in the game are a group of consumers and two companies from the industry. This model gives an explanation for the serious trust crisis of product quality facing domestic food and drug industries. The study found that compared with the quality information asymmetry of individual companies, industrial-level information asymmetry is the root cause of the trust crisis in industries such as the food and drug industries. When information is symmetrical at the industrial level, companies will keep providing high-quality products. When information becomes asymmetric, in the face of low-quality product competitors, companies persisting in high-quality products will prefer to provide low-quality products, triggering an industrial-level trust crisis. From the above research results, it is concluded that only when information asymmetry in the green agricultural products market is minimized, can repeated transactions be obtained between buyers and sellers and an effective third-party monitoring be provided, driving the substantial growth of the green agricultural product market.

\subsection{Research on the Cooperation between Producers and Consumers of Green Agricultural Products}

Community-supported agriculture (CSA) has become an important model for the development of green agricultural product market. CSA is a direct sale model in which consumers order foods from producers and pay in advance. Producers promise to use organic or similarly alternative production methods to produce and regularly supply fresh foods to consumers. It is an agricultural development model emphasizing communication, interaction, and mutual trust between producers and consumers as well as social and ecological sustainability [33-36]. Compared with other sale models, CSA alleviates the problem of information asymmetry in the green agricultural product market to a certain extent. 
Consumers and producers can basically realize a repeated game, which helps to avoid the risk of the moral hazards of CSA producers and, eventually, to boost the cooperation and mutual trust between consumers and producers [36]. CSA has received extensive attention and recognition, and many scholars even regard it as the hope of sustainable agricultural development [37,38]. However, compared with industrialized agriculture, CSA is still not well-developed. The reasons for this are as follows: (1) in real situations, the producers and consumers of CSA mainly interact in bazaars, farms, or via delivery. Ultimately, limited by geospatial conditions and high agricultural product prices, many consumers fail to get access to the CSA system; (2) the high cost of reconstructing mutual trust, the complex procedures and the high cost of certification, and other reasons hinder green agricultural producers from justifying that their foods are healthy and safe and that their products are officially certificated [39]. Facing reliable food produced by large-scale industrialization companies, CSA loses its market confidence, brands, and price advantages; (3) the short-span cycle of food supply and limited variety and quantity of food supply force CSA farms to explore new business models and find new partners. However, frictions and problems emerge over profit distribution, management, food safety supervision, and accountability among the CSA farms [36]. The above research results show that the CSA model changes the green agricultural product market from a single game to a repeated game, which can partially solve the problem of the development difficulties in the green agricultural product market while issues of major producer's moral crisis, consumer confidence, and economies of scale remain to be solved.

In summary, previous studies have provided a persuasive explanation for the inability of the green agricultural product market to form such a mechanism, but few have explored the development path of the green agricultural product market from the perspective of cooperation. Theoretically, production and consumption are two aspects of the same issue that are mutually reinforcing and mutually restricting. The development of the green agricultural product market is a dynamic process that is determined by consumers (buyers) and promoted by producers (sellers). There are two preconditions in a transaction: first, the transaction can increase the total revenue of both parties; second, the parties involved have a certain level of trust on transaction partners and other related objects. Hindered by major food safety incidents in recent years, the consumers' overall trust on the Chinese food industry has waned to a certain degree. In most cases, when people's attention to an incident has not completely diverged, a new round of scandals quickly cause the food industry to sink deeper into the "low quality, little trust" quagmire [32]. Therefore, it is difficult to establish trust in the green agricultural product market solely through producers or intermediaries. One of the most effective ways to build trust is to increase the game chains and change the one-shot game to a repeated game, which is difficult to achieve in non-cooperative games. Fafchamps [40] believes that the low efficiency of information transmission and the feedback on the agricultural products value chain will lead to a decline in the quality and safety of agricultural products. If the information platform is constructed and optimized, both buyers and sellers will adopt positive methods to actively pursue long-term and stable cooperation. Wei [41] points out that since the basic methodology of mainstream economics emphasizes that everyone is pursuing utility maximization, sometimes economics is mistakenly believed to be a discipline that advocates personal interests and individualism. On the contrary, it is a big misunderstanding. Economics actually advocates "cooperation works, isolation fails". Economics not only makes people aware of the existence of prisoners' dilemma, but also reminds people of the necessity and possibility of solving the prisoner's dilemma in a dynamic process. In other words, cooperative work is more efficient than solo work for one's own advantages.

In view of this, this paper aims to solve the crisis of trust in the green agricultural product market based on the CSA model and with the e-commerce platform of green agricultural products at the core and produce a development model where producers, consumers, and food safety inspection departments cooperate with platform providers. TU cooperative game theory will demonstrate the feasibility of this model with a view to providing a theoretical reference for the design of the related 
mechanisms for China's agricultural supply-side reform and the construction of a green agricultural e-commerce platform.

\section{Conceptual Model of the Relationship between the Main Bodies of the Green Agricultural Market}

Theoretically, the production and consumption of green agricultural products can be regarded as a process in a cooperative game, with the e-commerce platform as its core and the involvement of producers and consumers. The development model of the green agricultural market in which producers, consumers, food safety inspection departments, and partners of platform cooperate is shown in Figure 2.

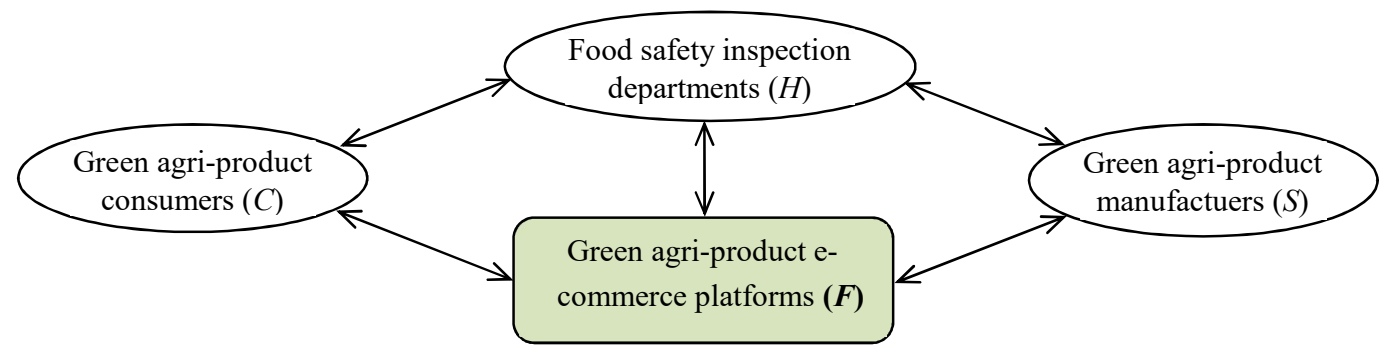

Figure 2. The conceptual model of the relationship between the main bodies of the green agricultural market with e-commerce platforms as the core.

What follows is where the relationship between the main bodies is shown:

(1) With the support of government policies, e-commerce platforms for green agricultural products are set up by competent companies or entrepreneurs. Such e-commerce platforms, different from those like Alibaba's, Taobao, or Tmall, should guarantee the quality of the green agricultural products they sell and their income should mainly come from commissions.

(2) Either e-commerce platform operators or producers should find the other. Those who do not have the certification of green agro-products will be sifted out by food safety inspection departments. The e-commerce platforms basically integrate the information of all the participants in the whole country and they disclose the products' details including whole origin, production capacity, production process, and inspection reports.

(3) On e-commerce platforms, producers release group-buying news, covering a variety of agricultural products, the estimated amount, prices, premium, delivery date, compensation terms on default, quality, exemption clauses for non-delivery due to natural disasters, and selling range. For fresh agro-product only sold locally, they also provide information about the delivery range.

(4) Consumers' group-purchases on e-commerce platforms can solve the problem that green agricultural producers cannot achieve economies of scale.

(5) E-commerce platforms are responsible for the sample-testing of green agricultural products (drawing samples and sending them to food safety inspection departments) and publishing the test results. If the default occurs, compensation shall be made in accordance with a cooperative agreement and liabilities claimed.

The size of the alliance and number of participants are set as follows. Assume the total number of participants in the cooperative game of green agricultural market $n=4$ and the set of participants $n=\{C, S, H, F\}$, where $C$ refers to consumers, $S$ refers to producers, $H$ refers to food safety inspection departments, and $F$ refers to e-commerce platforms.

Now, consider the supply and demand for a series of agricultural products. The agro-products with the same quality are categorized into one kind. For each kind, the supply of the producers' and demand of the consumers should be taken into consideration:

Let the set of agro-product consumers be $C=\left\{c_{j}\right\}$ and the individual consumer be $c_{i}$; 
Let the set of agro-product producers be $S=\left\{s_{i}\right\}$ and the individual producers be $s_{i}$;

$H=\left\{h_{i}\right\}$ is the set of food quality and safety inspectors who conduct sample tests and provide information on food quality and safety for every consumer.

$F$ stands for the e-commerce platforms that send the information about the demand and supply of these kinds of agro-products to each producer and consumer, respectively, and match the two sides accordingly.

Now, set a presumed price for this kind of product. The demand of $c_{j}$ for the products is $q_{j}=q_{j}(P)$. Assume $q_{j}(\cdot)$ is a decreasing continuous function related to price $P$. The demand aggregate for this kind of agricultural product can be expressed as follows:

$$
Q=\sum_{j} q_{j}(P) \equiv Q_{D}(P)
$$

Undoubtedly, $Q_{S}(\cdot)$ is an increasing continuous function of $P$. The inverse function of supply aggregate is

$$
P=P_{D}(Q)
$$

It is a decreasing continuous function too.

Likewise, when it comes to supply, assume the supply of each producer $s_{i}$ is an increasing continuous function $q_{i}=q_{i}(P)$ and the supply aggregate is

$$
Q=\sum_{i} q_{i}(P) \equiv Q_{S}(P)
$$

Since $Q_{S}(\cdot)$ is also an increasing continuous function of $P$, the inverse function of the supply aggregate is

$$
P=P_{S}(Q)
$$

When the information is complete, producers have a complete understanding of the requirements of product quality and the consumption demand of consumers, and consumers have a complete understanding of the production capacity and product quality from producers. Under such circumstances, the agricultural market is a perfectly competitive market. Its equilibrium price and quantity are determined by the following equations:

$$
P=P_{D}(Q), P=P_{S}(Q)
$$

Now, consumers and producers, as two groups, see their economic surplus maximized.

Let us assume that the total surplus of the producers outnumbers the total fixed cost, meaning that producers attain (short-term) excess profit as a whole. We take $w$ as the sum of the producers' total profit and consumers' total surplus.

$$
w=(\text { producers' surplus }- \text { producers' fixed cost })+\text { consumers' total surplus }
$$

The profit of individual producers is determined by the equilibrium price and the supply function of the individual producer. The short-term profit of producers that are involved in the process of production must be $\geq$ zero. Similarly, the economic surplus of an individual consumer is determined by the market equilibrium price and the function of individual demand; therefore, the economic surplus of consumers that make consumptions is definitely not less than zero.

Two reasons can be found for why the information could be incomplete. On the one hand, since consumers are not clear about the quality and safety of agricultural products, they have few demands for those products claimed to be of high-quality, but expensive. On the other hand, the low demand from consumers prompts producers to lessen their supply of high-quality agro-products. If the incomplete and the asymmetric information is not improved, the demand and supply curves 
in Figure 3 will move to the left. As a result, the producer surplus and consumer surplus will shrink sharply; or worse, the surplus from producers will barely cover the fixed cost and this will eventually lead to the collapse of the high-quality agricultural product market.

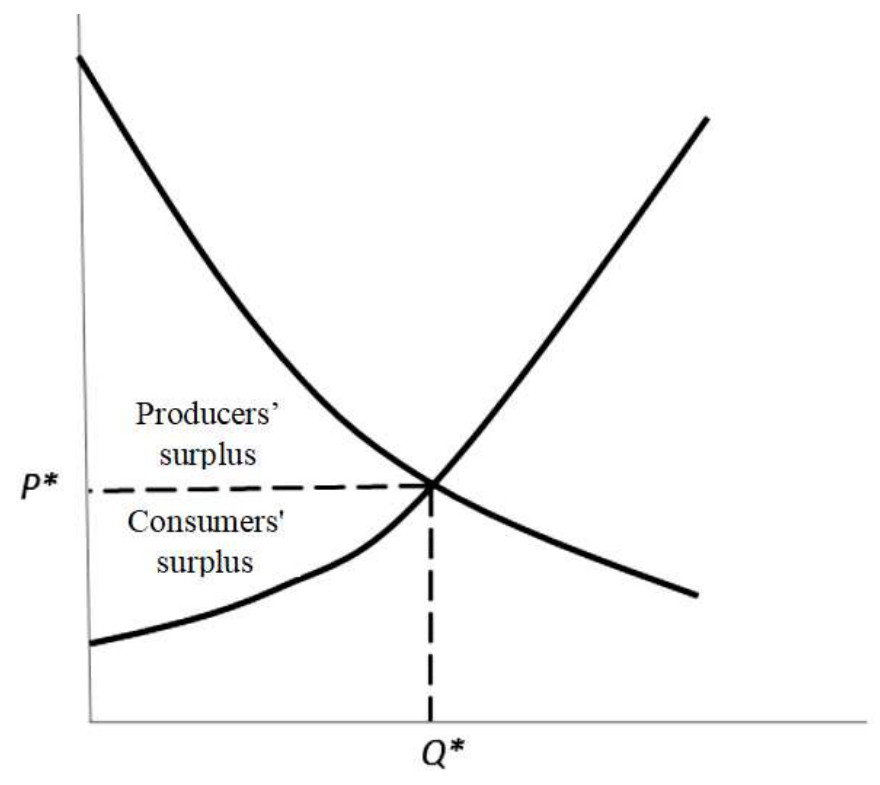

Figure 3. The supply and demand curve of green agricultural products and the producers' and consumers' surpluses.

In such a scenario, the issue of incomplete and asymmetric information can be tackled if the e-commerce platforms $F$ and food quality inspectors $H$ are engaged. If we put this matter into the framework of a TU coalition game, it is clear that it is because of the participation of $F$ and $H$ that producer surplus and consumer surplus can be maximized. Therefore, their contribution to the result of coalition $N$ is apparent. Accordingly, the characteristic function of the coalition game is built in this thesis with $f$ and $h$ denoting the operating costs of the green agricultural product e-commerce platforms and food quality inspectors, respectively.

In the characteristic function $v$, we define the following:

$$
\begin{aligned}
& v(S)=v(C)=v(F)=v(H)=0 \\
& v(\{S, C\})=v(\{S, F\})=v(\{S, H\})=v(\{C, F\})=v(\{C, H\})=v(\{F, H\})=0 \\
& v(\{S, C, F\})=x-f, v(\{S, C, H\})=y-h, v(\{S, F, H\})=v(\{C, F, H\})=0 \\
& v(\{S, C, F, H\})=w-f-h
\end{aligned}
$$

As long as a coalition does not include both producers and consumers, its value must be zero. In fact, the value of alliance $w-f-h$ equals the total benefit of producers brought by a competitive market with complete information while the operating costs of the e-commerce platforms and quality inspectors are deducted. For the coalition $\{S, C, F\}$, without the presence of quality inspectors, consumers are unable to have an instant and in-depth understanding of the quality and safety of agricultural products. Thus, their demands are relatively low and the benefits of producers and consumers are less. As for the coalition $\{S, C, H\}$, without the presence of e-commerce platforms, producers lack the knowledge of the demand from consumers. Since consumers are already poorly aware of the supply, the two sides make matching very highly expensive and the benefits to producers and consumers $y$ are inadequate. It is reasonable to believe the following:

$$
\max \{x-f, y-h\}<w-f-h
$$


Among them, $f$, the operation cost of green agricultural e-commerce platforms and $h$, that of quality inspectors, should meet the condition given below:

$$
w-h-x>0, w-f-y>0 .
$$

Definition 1. A division of the total welfare $w-f-h$ brought by the great coalition,

$$
w-f-h=w_{S}+w_{C}+w_{F}+w_{H}
$$

If the following conditions are met, $w-f-h$ is a nucleus:

$$
\begin{aligned}
& w_{S} \geq 0, w_{C} \geq 0, w_{F} \geq 0, w_{H} \geq 0 ; \\
& w_{S}+w_{C} \geq 0, w_{S}+w_{F} \geq 0, w_{S}+w_{H} \geq 0, w_{C}+w_{F} \geq 0, w_{C}+w_{H} \geq 0, w_{F}+w_{H} \geq 0 ; \\
& w_{S}+w_{C}+w_{F} \geq x-f, w_{S}+w_{C}+w_{H} \geq y-h, w_{S}+w_{F}+w_{H} \geq 0, w_{C}+w_{F}+w_{H} \geq 0 .
\end{aligned}
$$

It should be noticed that $w_{S}, w_{C}, w_{F}, w_{H}$ stand for the total profit of the producers, the total economic surplus of the consumers, and the profit of green agricultural product e-commerce platforms and that of quality inspectors, respectively.

\section{Non-Empty Core Verification and Shapley Value Solution of the Cooperative Game in Green Agricultural Product Market}

\subsection{Non-Empty Core Verification of the Cooperative Game in the Green Agricultural Product Market}

In order to ensure that the network of supply and demand for green agricultural products is constantly stable, it is crucial to establish a cooperative game model centered on green agricultural product e-commerce platforms and find out its nucleus solution. The emptiness of the nucleus solution depends on whether the set of route rejection participants is empty or not. Only when the nucleus is non-empty can it be assured that all the participants in the network will have properly distributed profit or income. Consequently, the network is able to operate stably and the market can be born and developed. Therefore, this paper proposes Proposition 1.

Proposition 1. We assume that the sum of the operating costs of e-commerce platforms and quality inspectors are less than $w$, then the core of the TU coalition game in Definition 1 is non-empty.

Only one nucleus needs to be verified and the process of verification is shown below

$$
\delta=\min \{w-f-h, w-h-x, w-f-y\}>0
$$

Suppose

$$
w_{S}=w_{C}=\frac{w-f-h-\delta}{2}, w_{F}=w_{H}=\frac{\delta}{2}
$$

So

$$
\begin{aligned}
& w_{S}+w_{C}+w_{F}+w_{H}=w-f-h ; \\
& w_{S}>0, w_{C}>0, w_{F}>0, w_{H}>0 ; \\
& w_{S}+w_{C}>0, w_{S}+w_{F}>0, w_{S}+w_{H}>0, w_{C}+w_{F}>0, w_{C}+w_{H}>0, w_{F}+w_{H}>0 ; \\
& w_{S}+w_{C}+w_{F}=w-f-h-\frac{\delta}{2}=\left(w-h-x-\frac{\delta}{2}\right)+x-f>x-f \\
& w_{S}+w_{C}+w_{H}>w-f-h-\frac{\delta}{2}=\left(w-f-y-\frac{\delta}{2}\right)+y-h>y-h \\
& w_{S}+w_{F}+w_{H}>0, w_{C}+w_{F}+w_{H}>0 ;
\end{aligned}
$$

Proposition 1 is verified. 
In practice, first of all, it is conceivable that the cooperation among $S, C, F, H$ first makes "total producer's profit + total consumer's surplus $=w$ ". Then, producers and consumers share the cost and profit of the platforms and inspectors in proportion to the profit or economic surplus.

An example: 100 consumers and 10 producers exist with an individual demand of $q_{j}=20-P$, an individual supply of $q_{i}=10 P$, a market demand of $Q=2000-100 P$, and a market supply of $Q=100 P$. The equilibrium price $P *=10$ and equilibrium quantity $Q *=1000$ in a competitive market with be the complete information. The fixed cost for the individual producer is 100 . The total producers' profit is $5000-10 \times 100=4000$, in which the individual producer's profit is 400 , the total consumers' surplus is 5000, and the individual consumer surplus is 50 .

$$
w=9000, f=1000, h=800, x=y=5000
$$

One of the nuclei is as follows:

$$
w_{S}=3000, w_{C}=3500, w_{F}=500, w_{H}=200
$$

The individual producers' profit is 300 and the individual consumers' surplus is 35 .

\subsection{Shapley Value Solution for the Cooperative Game in the Green Agricultural Product Market}

In theory, a nucleus result, though existing, is not unique normally. Such an issue can be solved by calculating its Shapley value and it is common within the nucleus. The marginal contribution function of participants participating in different alliance orders is demonstrated in Table 1.

\begin{tabular}{|c|c|c|c|c|}
\hline Order Alliance & $\begin{array}{l}\text { Green Agri-Product } \\
\text { Manufacturers (S) }\end{array}$ & $\begin{array}{l}\text { Green Agri-Product } \\
\text { Consumers (C) }\end{array}$ & $\begin{array}{c}\text { Green Agri-Product } \\
\text { E-Commerce Platforms (F) }\end{array}$ & $\begin{array}{c}\text { Food Safety Inspection } \\
\text { Departments (H) }\end{array}$ \\
\hline S-C-F-H & 0 & 0 & $x-f$ & $w-h-x$ \\
\hline$S-C-H-F$ & 0 & 0 & $y-h$ & $w-h-x$ \\
\hline$S-F-C-H$ & 0 & $x-f$ & 0 & $w-h-x$ \\
\hline$S-F-H-C$ & 0 & $w-f-h$ & 0 & 0 \\
\hline S-H-C-F & 0 & $y-h$ & $w-f-y$ & 0 \\
\hline$S-H-F-C$ & 0 & $w-f-h$ & 0 & 0 \\
\hline F-C-S-H & $x-f$ & 0 & 0 & $w-h-x$ \\
\hline F-C-H-S & $w-f-h$ & 0 & 0 & 0 \\
\hline$F-S-C-H$ & 0 & $x-f$ & 0 & $w-h-x$ \\
\hline F-S-H-C & 0 & $w-f-h$ & 0 & 0 \\
\hline F-H-C-S & $w-f-h$ & 0 & 0 & 0 \\
\hline F-H-S-C & 0 & $w-f-h$ & 0 & 0 \\
\hline C-S-F-H & 0 & 0 & $x-f$ & $w-h-x$ \\
\hline C-S-H-F & 0 & 0 & $y-h$ & $w-h-x$ \\
\hline C-F-S-H & $x-f$ & 0 & 0 & $w-h-x$ \\
\hline C-F-H-S & $w-f-h$ & 0 & 0 & 0 \\
\hline$C-H-S-F$ & $y-h$ & 0 & $w-f-y$ & 0 \\
\hline C-H-F-S & $w-f-h$ & 0 & 0 & 0 \\
\hline$H-C-S-F$ & $y-h$ & 0 & $w-f-y$ & 0 \\
\hline$H-C-F-S$ & $w-f-h$ & 0 & 0 & 0 \\
\hline$H-S-C-F$ & 0 & $y-h$ & $w-f-y$ & 0 \\
\hline$H-S-F-C$ & 0 & $w-f-h$ & 0 & 0 \\
\hline$H-F-C-S$ & $w-f-h$ & 0 & 0 & 0 \\
\hline$H-F-S-C$ & 0 & $w-f-h$ & 0 & 0 \\
\hline
\end{tabular}

Table 1. The marginal contribution function of participants participating in different alliance orders.

Normally,

$$
v(\{S, C, F, H\})=w-f-h, v(\{S, C, F\})=x-f, v(\{S, C, H\})=y-h, v(S)=0 \text { for others }
$$

First, consider the contribution of $F$ which joins the alliance in the third place. At this point, the contribution $a w-f$ occurs only when $S, C$ are the first and second ones to join in. This happens 
twice. Let us think about it again when $F$ is the last one to join in (six times). Every time, its contributions are as follows:

$$
w-f-h-(y-h)=w-y-f
$$

and the average contribution is as follows:

$$
\frac{2(x-f)+6[w-y-f]}{24}
$$

This is the due amount of its profit.

As such, the Shapley value of a TU cooperative game in the green agricultural product market is given below:

$$
\left(\frac{6 w-8 f-8 h+2 x+2 y}{24}, \frac{6 w-8 f-8 h+2 x+2 y}{24}, \frac{4 w-6 f-2 h+2 x-2 y}{24}, \frac{8 w-6 h-2 f-6 x+2 y}{24}\right)
$$

Now, make a further analysis based on the example of the last section:

Suppose, $v(\{S, C, F, H\})=7200, v(\{S, C, F\})=4000, v(\{S, C, H\})=3200, v(S)=0$ for others, the marginal contribution value of participants participating in different alliance orders is presented in

\begin{tabular}{|c|c|c|c|c|c|}
\hline Alliance & Order & $\begin{array}{l}\text { Green Agri-Product } \\
\text { Manufacturers (S) }\end{array}$ & $\begin{array}{l}\text { Green Agri-Product } \\
\text { Consumers (C) }\end{array}$ & $\begin{array}{c}\text { Green Agri-Product } \\
\text { E-Commerce Platforms (F) }\end{array}$ & $\begin{array}{c}\text { Food Safety Inspection } \\
\text { Departments (H) }\end{array}$ \\
\hline$S-C-F-H$ & & 0 & 0 & 4000 & 3200 \\
\hline S-C-H-F & & 0 & 0 & 4000 & 3200 \\
\hline$S-F-C-H$ & & 0 & 4000 & 0 & 3200 \\
\hline$S-F-H-C$ & & 0 & 7200 & 0 & 0 \\
\hline$S-H-C-F$ & & 0 & 3200 & 4000 & 0 \\
\hline$S-H-F-C$ & & 0 & 7200 & 0 & 0 \\
\hline$F-C-S-H$ & & 4000 & 0 & 0 & 3200 \\
\hline$F-C-H-S$ & & 7200 & 0 & 0 & 0 \\
\hline$F-S-C-H$ & & 0 & 4000 & 0 & 3200 \\
\hline F-S-H-C & & 0 & 7200 & 0 & 0 \\
\hline$F-H-C-S$ & & 7200 & 0 & 0 & 0 \\
\hline$F-H-S-C$ & & 0 & 7200 & 0 & 0 \\
\hline$C-S-F-H$ & & 0 & 0 & 4000 & 3200 \\
\hline$C-S-H-F$ & & 0 & 0 & 4000 & 3200 \\
\hline C-F-S-H & & 4000 & 0 & 0 & 3200 \\
\hline$C-F-H-S$ & & 7200 & 0 & 0 & 0 \\
\hline$C-H-S-F$ & & 3200 & 0 & 4000 & 0 \\
\hline$C-H-F-S$ & & 7200 & 0 & 0 & 0 \\
\hline$H-C-S-F$ & & 3200 & 0 & 4000 & 0 \\
\hline$H-C-F-S$ & & 7200 & 0 & 0 & 0 \\
\hline$H-S-C-F$ & & 0 & 3200 & 4000 & 0 \\
\hline$H-S-F-C$ & & 0 & 7200 & 0 & 0 \\
\hline$H-F-C-S$ & & 7200 & 0 & 0 & 0 \\
\hline$H-F-S-C$ & & 0 & 7200 & 0 & 0 \\
\hline
\end{tabular}
Table 2.

Table 2. The marginal contribution value of participants participating in different alliance orders.

Through calculation, the Shapley value is $(2400,2400,1333.33,1066.67)$.

\section{Discussion}

\subsection{Results Discussion}

While green agriculture can improve biodiversity, increase farmers' income, reduce agricultural non-point source pollution, and solve food safety issues, the Chinese government is also aware of the importance of the green transformation of agriculture for the sustainable development of China. In 2015, the Central Document No. 1 proposed a strategic task of "deepening the structural adjustment of agriculture". Starting from the supply-side structural reform, it aims to increase the supply of green, organic, and safe agricultural products, reduce the supply of general agricultural products, 
and boost the supply of special agricultural products. In 2017, the Central Document No. 1 proposed the "pushing green production methods and enhancing the sustainable development of agriculture". Is it possible to solve the current problem in the agricultural green transformation by carrying out supply-side structural reforms and encouraging producers to produce high quality green agricultural products? According to the calculation results of this paper, the answer is negative. If there is no large number of consumers who have a purchasing power and believe that producers can provide true green agricultural products, green agricultural product producers will not be able to make a profit, and they will eventually be transformed to produce ordinary agricultural products. Thus, China's green agricultural product market will not develop.

According to the marginal contribution value of participants participating in different alliance orders, we can see that (1) when consumers implement group buying through the green agricultural product e-commerce platform, the value of the marginal contribution of green agricultural producers entering the alliance is the largest and producers can easily achieve economies of scale. However, the precondition is that the producers of green agricultural products believe that the group purchase can finally reach a transaction. Therefore, whether or not the green agricultural product e-commerce platform can realize these guarantees is extremely important. In this case, the producers of green agricultural products have the lowest risk, they are easy to believe in the market, and they produce green agricultural products according to the standards. (2) When producers, food safety inspection departments, and platform vendors achieve alliances and producers publish green farm product custom group purchase information or retail information through the green agricultural e-commerce platform, the marginal contribution value of consumers entering the alliance is the largest. However, the premise is that consumers believe that the alliance can provide real green agricultural products. Therefore, it is extremely important that the green agricultural product e-commerce platform guarantees the quality of green agricultural products. In this case, the cost for consumers to search for green agricultural products is minimal and they will be more likely to believe in green agricultural producers because of the guarantee of the green agricultural e-commerce platform. However, the retail model does not apply to fresh produce with a short shelf life.

Other scholars in China only proposed to establish a market mechanism for high-quality green agricultural products [42] and establish a production and circulation mechanism for high quality and safe agricultural products [43]. However, this paper further explored the specific models for how to promote the development of the green agricultural products market. Compared with past related research, this research results have a higher reference value to China's future green agricultural transformation.

\subsection{Limitation of the Studies and Problems to Be Further Studied in the Future}

Limitation of the studies: first, since there is no four-party coalition of producers, consumers, food safety inspection departments, and e-commerce platforms at hand, the actual data of coalition parties cannot be obtained. In this paper, we can only use hypothetical examples to analyze the marginal contribution value of participants in different coalition orders in a TU cooperative game and calculate the Shapley value of the coalition. Secondly, in Shapley itself there exist some problems, such as excluding the cooperation risk of each player [44].

Problems to be further studied in the future: first, based on actual data on green agricultural products, the follow-up study will further verify the effectiveness of the multilateral coalition to develop a green agricultural product market. Secondly, under the conditions of reciprocal motives, when the green agricultural product e-commerce platform provides guarantees for the realization of consumer group purchase transactions, and purchase the agricultural products that remain due to individual consumer defaults, the follow-up study will analyze the cooperative behavior between the green agricultural product producers and the e-commerce platform. Thirdly, under the conditions of reciprocal motives, when the green agricultural e-commerce platform provides guarantees for the 
quality of green agricultural products, the follow-up study will analyze the cooperative behavior of consumers of green agricultural products and the e-commerce platform.

\section{Conclusions and Policy Implication}

\subsection{Conclusions}

CSA has received extensive attention and recognition, and many scholars even regard it as the hope of sustainable agricultural development $[37,38]$. However, it cannot solve the problems of producers' moral crisis, consumer confidence, and economies of scale. There must be a middleman who can guarantee the quality of the products in order to solve the current difficulties in the development of China's green agricultural products market.

By applying the TU cooperative game method and basing it on theoretical analyses and hypothetical data, this paper proves that it is effective to apply the green agricultural product market development model in which there is cooperation among the producers, consumers, food safety inspection departments, and the e-commerce platforms as it meets the objective requirements of the times and the market economy. Based on the marginal contribution value of participants in different coalition orders, this paper finds that there are six kinds of coalition orders. The green agricultural producers (S) and consumer (C) enter the coalition in the last place, and the marginal contribution value is maximized. This demonstrates the importance of the supply side and the demand side of green agricultural products and that the production and consumption are two sides of a coin. To be specific, the development of a green agricultural product market is a dynamic process that is decided by consumers and promoted by producers. They promote and restrict each other. When the green agricultural product market development model with an e-commerce platform as the core is successfully applied, recognized, and trusted by consumers as well as producers, a large number of green agricultural producers and consumers will enter into the coalition and promote the development of the aforementioned green agricultural product market.

\subsection{Policy Recommendation}

Based on the findings of this paper, the Chinese government only attaches great importance to carrying out structural reforms on the supply side and encourages producers to produce high-quality green agricultural products. This cannot achieve the development of China's green agricultural products market. Therefore, the Chinese government should encourage powerful companies to build a professional green agricultural product e-commerce platform to achieve a coalition of green agricultural producers, consumers, inspection departments, and platform providers. Our specific recommendations are as follows: (1) at the national level, to clearly propose a strategy to build a green agricultural product e-commerce platform in China. In September 2017, the "Opinions on Innovating the Institutional Mechanism to Promote Green Agricultural Development" issued by the COCPC and GOSC [45] merely proposed the "establishment of a green agricultural standard system" and did not address how to solve the problems in the development of China's green agricultural product market. Therefore, based on the research results of this paper, this paper proposes to incorporate the suggestion of "building a professional e-commerce platform for green agricultural products in China" into this opinion, clarifying that the e-commerce platform should be able to provide guarantees on the quality of green agricultural products; to change the green agricultural products market from a single game to a repeated game; to solve the moral crises of producers, consumer trust, and economies of scale; and to solve other problems. (2) To launch a pilot application of specialized e-commerce platform for green agricultural products in the Guizhou province. In May 2017, the General Office of the Guizhou Provincial Government issued the "Implementation Plan for Promoting Green and High-quality Agricultural Products in the Guizhou Province", which proposes to "build a global e-commerce poverty reduction conference and use online platforms to increase the marketing campaigns to ensure that the average amount of e-commerce transactions for key agricultural products grows by more than $50 \%$ annually" [46]. 
Given the determination of the Guizhou province to develop the green agricultural product market, it can more easily promote the alliance of producers, consumers, food safety inspection departments, and platform traders. Therefore, this paper believes that China can carry out the "specialized pilot application of a green agricultural products e-commerce platform" in the Guizhou province.

Author Contributions: M.D. and S.Y. conceived and established the study framework; M.D., G.X., S.Y. wrote the paper.

Acknowledgments: This study was financially supported by Hunan Provincial Natural Science Foundation of China, "Research on the Pseudo-social Responsibility of Listed Companies Based on Stakeholder Perspective" (Grant Number 2017JJ2094), and the general program of Philosophy and Social Science Foundation of Hunan Province, China, "Research on the Mechanism of Controlling Ammonia for Eliminating Haze in China's Agriculture under the Concept of Green Development" (Grant Number 17YBA156), and the Research Foundation of Education Bureau of Hunan Province, China, "Research on the Evolutionary Path and Guiding Policy of Enterprise Environmental Management Behavior: A Case Study of the Resource-Conserving and Environment-Friendly Society Experiment Area" (Grant Number 15B092).

Conflicts of Interest: The authors declare no conflict of interest.

\section{References}

1. Yan, L.; Deng, Y.; Cai, Y.; Xu, L. Analysis of the externality of green agriculture development. World Surv. 2009, 8, 11-14.

2. Yu, X.; Gao, Z.; Zeng, Y. Willingness to pay for the "green food" in china. Food Policy 2014, 45, 80-87. [CrossRef]

3. Baranski, M.; Srednicka, T.D.; Volakakis, N.; Seal, C.; Sanderson, R.; Stewart, G.B.; Benbrook, C.; Biavati, B.; Markellou, E.; Giotis, C.; et al. Higher antioxidant and lower cadmium concentrations and lower incidence of pesticide residues in organically grown crops: A systematic literature review and meta-analyses. $\mathrm{Br}$. J. Nutr. 2014, 112, 794-811. [CrossRef] [PubMed]

4. Pamfilie, R.; Voinea, L. Innovation management-Applications in the foodstuff offer field. Qual. Access Success 2009, 10, 7-8.

5. Aceleanu, M. Sustainability and competitiveness of romanian farms through organic agriculture. Sustainability 2016, 8, 245. [CrossRef]

6. Mohamad, R.S.; Verrastro, V.; Cardone, G.; Bteich, M.R.; Favia, M.; Moretti, M.; Roma, R. Optimization of organic and conventional olive agricultural practices from a Life Cycle Assessment and Life Cycle Costing perspectives. J. Clean. Prod. 2014, 70, 78-89. [CrossRef]

7. United Nations Environment Programme (UNEP). Towards a Green Economy: Pathways to Sustainable Development and Poverty Eradication; United Nations Environment Programme: Nairobi, Kenya, 2011.

8. Crowder, D.; Reganold, J. Financial competitiveness of organic agriculture on a global scale. Proc. Natl. Acad. Sci. USA 2015, 112, 7611-7616. [CrossRef] [PubMed]

9. Deng, L.Y. Major study on ammonia control. Century Wkly. 2014, 35, 62-64.

10. CGFDC (China Green Food Development Center). Green Food Statistical Yearbook. Available online: http:/ / www.moa.gov.cn/sydw/lssp/zl/tjnb/ (accessed on 12 October 2016).

11. Ni, X.Z. Research on the effective supply of green agricultural products in china. Issues Agric. Econ. 2012, 4, $18-21$.

12. Zago, A. A Nonparametric analysis of production models with multidimensional quality. Am. J. Agric. Econ. 2010, 91, 751-764. [CrossRef]

13. Maffioli, A.; Ubfal, D.; Baré, G.V.; Cerdán-Infantes, P. Extension services, product quality and yields: The case of grapes in argentina. Agric. Econ. 2011, 42, 727-734. [CrossRef]

14. Saenger, C.; Qaim, M.; Torero, M.; Viceisza, A. Contract farming and smallholder incentives to produce high quality: Experimental evidence from the Vietnamese dairy sector. Agric. Econ. 2013, 44, 297-308. [CrossRef]

15. Zhang, L.G. Analysis on the moral hazard in farmers' organic food production. Econ. Probl. 2008, 12, 93-96.

16. Zhu, D.; Zhang, X.L.; Niu, L.Y. Vegetable farmers' willingness to adopt biopesticides. China Popul. Resour. Environ. 2014, 24, 64-70.

17. Wang, Y.Q.; Liu, S.Y.; Du, J.L. Contagion effects vs. competitive effects in credence goods markets: Theory and event study on china's food markets. Econ. Res. J. 2014, 2, 141-154. 
18. Yin, S.J.; Wu, L.H.; Chen, M. Analysis of demand for organic foods based on willingness to pay. Agric. Technol. Econ. 2008, 5, 81-88.

19. Latvala, T.; Kola, J. Consumers' willingness to pay for additional information on food quality and safety. In Proceedings of the 84th EAAE Seminar on Food Safety in a Dynamic World, Zeist, The Netherlands, 8-11 February 2004.

20. Lee, H.J.; Yun, Z.S. Consumers' perceptions of organic food attributes and cognitive and affective attitudes as determinants of their purchase intentions toward organic food. Food Qual. Preference 2015, 39, $259-267$. [CrossRef]

21. Angulo, A.M.; Gil, J.M.; Tamburo, L. Food safety and consumers' willingness to pay for labelled beef in spain. J. Food Prod. Mark. 2005, 11, 89-105. [CrossRef]

22. Zhang, H.Y.; Wang, H.J. Empirical research on the willingness of consumption of green agricultural products and its influencing factors-Taking consumers in Guangzhou as an example. Agric. Technol. Econ. 2009, 6, 62-69.

23. Zhou, Y.H.; Wang, X.Q.; Ruan, X.H. Consumers' Analysis of the Purchase Behavior of Labeled Beef Traceable Beef-Based on the Survey of Shanghai Carrefour Supermarket. Chin. Rural Econ. 2008, 5, 22-32.

24. Jiang, B.C.; Zhu, Q.Y.; Ou, X.M. Experimental economic analysis of consumer willingness to pay and its premium in high-quality edible agricultural products: A questionnaire survey of pork supply to Hong Kong. Chin. Rural Econ. 2013, 2, 23-34.

25. Yu, M.; Zhao, L. Economic analysis of green agricultural product consumption intentions. Financ. Econ. Rev. 2007, 6, 85-91.

26. Hu, W.Z.; Zhou, Z.M.; Yan, Z.Y. Consumer information needs and development strategy of pork traceability system. Chin. J. Anim. Sci. 2010, 46, 23-26.

27. Zhao, R.; Qiao, J.; Sun, R.P. Consumers' attitudes, perceptions and purchase intentions of traceability foods: An analysis based on consumer surveys in Beijing and Xianyang cities. Consum. Econ. 2010, 3, 40-45.

28. Wirth, F.F.; Stanton, J.L.; Wiley, J.B. The relative importance of search versus credence product attributes: Organic and locally grown. Agric. Resour. Econ. Rev. 2011, 40, 48-62. [CrossRef]

29. Li, X. A signal display model for credence goods quality: Taking food safety as an example. World Econ. Pap. 2011, 1, 87-108.

30. Mcfadden, J.R.; Huffman, W.E. Willingness-to-pay for natural, organic, and conventional foods: The effects of information and meaningful labels. Food Policy 2017, 68, 214-232. [CrossRef]

31. Jin, M.; Zheng, S.F. Analysis of game behaviors in china's green agricultural product market. Financ. Trade Econ. 2006, 6, 38-41.

32. Li, X.; Shi, L. An economic explanation of industry confidence crisis: Taking food safety as an example. Econ. Res. J. 2014, 1, 169-181.

33. O'Hara, S.U.; Stagl, S. Global food markets and their local alternatives: A socio-ecological economic perspective. Popul. Environ. 2001, 22, 533-554. [CrossRef]

34. Brown, C.; Miller, S. The impacts of local markets: A review of research on farmers markets and community supported agriculture (CSA). Am. J. Agric. Econ. 2008, 90, 1296-1302. [CrossRef]

35. Feagan, R.; Henderson, A. Devon acres csa: Local struggles in a global food system. Agric. Hum. Values 2009, 26, 203-217. [CrossRef]

36. Dong, H.; Zheng, X.D.; Fang, X.M. The development of community supported agriculture: With the combination of theoretical foundation and international experience. Chin. Rural Econ. 2017, 1, 82-92.

37. Groh, T.; Mcfadden, S. Farms of Tomorrow Revisited: Community Supported Farms-Farm Supported Communities; Bio-Dynamic Farming \& Gardening Association: Milwaukee, WI, USA, 1997.

38. Henderson, E.; Gussow, J.D. Sharing the Harvest: A Citizen's Guide to Community Supported Agriculture; Chelsea Green Publishing: White River Junction, VT, USA, 2007.

39. Lu, J.X. The characteristics of alternative food systems and its development difficulties: A case study of community supported agriculture and the nested market. Guizhou Soc. Sci. 2016, 4, 158-162.

40. Fafchamps, M.; Hill, R.V.; Minten, B. Quality control in nonstaple food markets: Evidence from India. Agric. Econ. 2008, 38, 251-266. [CrossRef]

41. Wei, S.J. How Do Cross-Century Talents Grasp Cross-Century Opportunities? Available online: http:/ / www.econ.fudan.edu.cn/ newsdetail.php?cid=11463 (accessed on 26 June 2017). 
42. Li, G. On the transformation of kinetic energy in China's agricultural development. China's Rural Econ. 2017, 7, 2-14.

43. Yang, G. Research on coordination mechanism of production and circulation of agricultural products-Based on the perspective of structural reforms in the supply side of agriculture. Rural Econ. 2017, 10, 64-67.

44. Liu, J.; He, D. Profit allocation of hybrid power system planning in energy internet: A cooperative game study. Sustainability 2018, 10, 388. [CrossRef]

45. COCPC (Central Office of the Communist Party of China); GOSC (General Office of the State Council). Opinions on Innovating the Institutional Mechanism to Promote Green Agricultural Development. Available online: http://www.gov.cn/xinwen/2017-09/30/content_5228960.htm (accessed on 30 September 2017).

46. General Office of the Guizhou Provincial Government. Implementation Plan for Promoting Green and High-Quality Agricultural Products in Guizhou Province. Available online: http:/ /www.gzgov.gov.cn/ xwzx/djfb/201705/t20170510_729002.html (accessed on 10 May 2017).

(C) 2018 by the authors. Licensee MDPI, Basel, Switzerland. This article is an open access article distributed under the terms and conditions of the Creative Commons Attribution (CC BY) license (http://creativecommons.org/licenses/by/4.0/). 